\title{
Developing a competitive intelligence strategy framework supporting the competitive intelligence needs of a financial institution's decision makers
}

Authors:
Tanya du Plessis ${ }^{1}$
Mzoxolo Gulwa ${ }^{1}$
Affiliations:
'Department of Information
and Knowledge Management,
University of Johannesburg,
South Africa
Corresponding author:
Tanya du Plessis,
tduplessis@uj.ac.za
Dates:
Received: 30 Nov. 2015
Accepted: 25 Apr. 2016
Published: 27 July 2016
code with your
How to cite this article:
Du Plessis, T. \& Gulwa, M.,
2016, 'Developing a
to read online.
competitive intelligence
strategy framework
supporting the competitive
intelligence needs of a
financial institution's decision
makers', South African
Journal of Information
Management 18(2), a726.
http://dx.doi.org/10.4102/
sajim.v18i2.726
Copyright:
(C) 2016. The Authors.
Licensee: AOSIS. This work
is licensed under the
Creative Commons
Attribution License.

Background: For competitive intelligence $(\mathrm{CI})$ to have the greatest contribution to strategic management, CI professionals require an in-depth understanding of the CI needs of decision makers. CI professionals have to carefully plan how to best inform corporate decision-making. A strategy framework is a planning tool which can be used to explore ways to enhance an organisation's strategic planning capabilities.

Objective: To investigate the CI needs of a financial institution's decision makers in order to develop a CI strategy framework. To present the strategy framework as a planning tool to CI professionals in the financial services industry as well as mapping the process of developing a planning tool, thereby enabling a financial institution's CI capability to better meet the CI needs of decision makers.

Method: The guiding paradigm of interpretivist research directed the research design of a single qualitative case study, using an inductive approach. Qualitative data analysis techniques were used, which included the use of numerical data, to develop a planning tool for CI professionals based on a thorough understanding of the CI needs of decision makers.

Results: Decision makers place considerable value on CI in terms of its contribution to strategy development, decision-making, gaining advantage over competitors and enhancing the financial performance of the organisation. Relationships between concepts and patterns or trends that were identified and utilised to establish themes in the data resulted in a 12-point strategy framework.

Conclusion: A financial institution's CI capability can be enhanced to better meet the CI needs of the organisation's decision makers when CI professionals carefully plan their approach of informing corporate decision-making. This paper presents a 12-point CI strategy framework as a planning tool for CI professionals.

\section{Introduction}

In recent years the global competitive scenario has grown in fierceness and intricacy (Zenaide \& Castro 2015:11). Phenomena such as globalisation, deregulation, dematerialisation, emerging economies, rapidly changing consumer behaviour, disruptive innovation and shortened life cycles of several products point to a hard-to-foresee panorama. Ghannay and Mamlouk (2015:35) add that 'organisations are struggling to survive in today's competitive business world', and that 'becoming and remaining competitive requires a conscious and continuous design for competitive advantage'.

Companies with the ability to emerge stronger from difficult economic conditions are those that, on the basis of correctly organised intelligence, base their new business plans on value, innovation and correct competitive strategy, followed by implementation and successful realisation in the market place (Bartes 2014b:1243). The emphasis is on having a basis of correctly organised intelligence. It is thus of critical importance that competitive intelligence (CI) professionals have a plan that will successfully elevate the synergies between CI and strategic management.

For CI to have the greatest contribution to strategic management, CI professionals need an indepth understanding of the CI needs of decision makers as well as the decision-making value they associate with CI. CI professionals have to carefully plan how to best inform corporate decision-making and a planning tool would be useful. A strategy framework is a planning tool which can be used to explore ways to enhance an organisation's strategic planning capabilities. 
This paper presents a strategy framework that could be used as a planning tool by CI professionals in the financial services industry.

The paper begins by stating the research question and objective, followed by a brief review of the value of $\mathrm{CI}$ in decision-making according to existing literature. The research methodology section motivates the research design, a single qualitative case study. The analysis of results and presentation of key findings section is followed by a 12-point CI strategy framework which was developed as a result of this study's inductive research approach. Lastly, the delimitation of the study is stated, the paper is concluded and recommendations are made as well as suggestions for further research.

\section{Research question and objective}

It is not always clear how CI professionals should best approach informing corporate decision-making. The main research question of the study was: How can the competitive intelligence needs of decision makers at a financial institution be better met? and data was collected in order to address these three sub-problems: (1) What are the CI needs of a financial institution's (FI's) decision makers? (2) What actions or elements constitute a strategy framework to be used as a planning tool by CI professionals in the financial services industry? (3) What does the process entail of developing a planning tool aimed at enabling a FI's CI capability to better meet the CI needs of decision makers?

The research objective was threefold: (1) investigating the CI needs of a FI's decision makers in order to develop a $\mathrm{CI}$ strategy framework, (2) presenting the strategy framework as a planning tool to CI professionals in the financial services industry and (3) mapping the process of developing a planning tool by which a FI's CI capability would be enabled to better meet the CI needs of decision makers. The research objective originated from existing knowledge of the value of $\mathrm{CI}$ in decision-making.

\section{Value of competitive intelligence in decision-making}

The value of $\mathrm{CI}$ in decision-making has been investigated and reported extensively in the studies of Du Toit and Muller (2004), Muller (2006), Botha and Boon (2008), Fleisher and Wright (2009), Heppes and Du Toit (2009), Wright, Eid and Fleisher (2009), Strauss and Du Toit (2010) and Du Toit and Sewdass (2014), to mention a few. Every business confronts some set of crucial business issues and strategic decisions i.e. a unique combination of specific competitive changes that need to be explored and specific choices that need to be made. Each business issue or strategic decision must be supported by vital, forward-looking intelligence (Fahey \& Herring 2007:13).

Fahey (2009:12) and Laney (2016) mention analysis tools and techniques that use data sources, technology and gathering methods unimaginable a generation ago; these tools now offer executives tantalising clues to new opportunities to achieve competitive advantage. However, companies consistently struggle to ensure that decision makers have timely and relevant intelligence for making strategic decisions (Naidoo 2003:61; Begg \& Du Toit 2007:2; Laney 2016). Strategic decisions by definition concern tomorrow and they have farreaching consequences for the future, which means that unpredictable changes in the areas of technology, demography, economy, globalisation and the environment need to be taken into account (Botterhuis et al. 2009:1).

Calof and Wright (2008:724) cited a study which found that CI supports strategic decisions in the areas of corporate or business strategy, sales or business development, market entry decisions, product development, research and development, technology decisions, mergers and acquisitions decisions, due diligence, joint venture decisions and regulators/legal responses. This reveals that $\mathrm{CI}$ influences a wide range of decision-making areas and is a vital ingredient in the formulation of business strategy (Calof \& Wright 2008:724).

The more information about the internal and external organisational environment that is considered within decision-making processes, the better the conclusions are about possible consequences of alternative actions leading to more successful decisions (Schiefer 2013:9). Lowenthal (2008:313) states that a key role of CI is to reduce uncertainty. In tough times, $\mathrm{CI}$ activity therefore has to increase in both intensity and frequency of supporting decision-making. Decision makers want to know what is happening as well as what is likely to happen in the near and far future.

Duvenage (2010:34) suggests that the decision-making 'window' is only open for a very short time due to the increasing speed with which transactions and events occur throughout the world as a result of the Internet, multimedia and other networks. Individuals and organisations are overwhelmed because events and patterns are enfolding so rapidly and non-linearly, leading to confusion, anxiety and ultimately decision paralysis. According to Duvenage (2010:34), the immediacy trend has an impact on intelligence as CI professionals have to compete with media and other information brokers who communicate and disseminate information on world events instantaneously through the multimedia, Internet and cell phone technology. This information is sometimes labelled, positioned and sold as intelligence (Duvenage 2010:34). This type of 'intelligence' is available to all in abundance. Instead, the value of $\mathrm{CI}$ in decision-making begins with establishing the relationship between strategic management and CI based on a thorough understanding of the specific CI needs of decision makers. This study set out to investigate decision makers' CI needs in order to develop a CI strategy framework. Qualitative inquiry was chosen as the appropriate research approach.

\section{Research methodology}

The interpretivist research paradigm directed the research design. A single qualitative case study research strategy was 
used with an inductive approach. A primary purpose of the inductive approach is to allow research findings to emerge from the frequent, dominant or significant themes inherent in raw data, without the restraints imposed by structured methodologies (Thomas 2003:2; Yin 2003; Saunders, Lewis \& Thornhill 2012:126). An inductive approach was suitable because the research intended to develop a CI strategy framework of relevance to a specific FI where no existing research on the CI needs of decision makers at the case organisation had been done previously.

The methods applied were aimed at collecting data that would contribute to action plans aimed at enhancing the CI services currently provided to decision makers at the case organisation. Qualitative data analysis techniques were used, which included the use of numerical data because quantification gives precision to statements, it enables themes in data to emerge with more clarity and highlights the meaning of findings by providing focus (Bauer, Gaskell \& Allum 2000:3-18; Sandelowski, Voils \& Knafl 2009:208). Maxwell (2010:480) states that the use of numerical data in qualitative research is a legitimate and valuable research strategy as this ensures that the process and procedures are orientated properly.

In order for this study to develop a planning tool for $\mathrm{CI}$ professionals, numerical data had to be collected that would provide a thorough understanding of the CI needs of decision makers. A self-administered questionnaire, including structured questions, was used as a data collection method. The population was the case organisation's managerial component and out of the targeted sample of 500 managers and executives, 124 respondents returned the questionnaire. Although the response rate was only $25 \%$, data analysis remained important to the case organisation because no other similar investigation had been conducted to date.

Questions were aimed at testing participants' understanding of strategic management ideals and establishing their CI needs in terms of topics and frequencies. Data was first statistically analysed as part of the scientific process of qualitative data analysis aimed at identifying relationships between concepts and patterns or trends and using these to establish themes in the data. A12-point CI strategy framework was then developed based on qualitative data analysis of empirical data and literature review with an inductive approach.

\section{Analysis and discussion of results}

In this study, the analysis and discussion of results formed an interrelated and interactive set of processes and findings typical of qualitative inquiry with an inductive approach (Saunders, Lewis \& Thornhill 2009:488). It was first established that a strategy framework is a planning tool which can be used to explore ways to enhance an organisation's strategic planning capabilities (Gould \& Desjardins 2015:319). From a planning perspective, a strategy framework aids decision makers in choosing a course of action for their organisation. The difference between a 'strategy framework' and 'framework' should be noted; the first is described as a 'planning tool' and is a precursor of the latter. The latter is a complete structure or system-wide comprehensive plan aimed at continuous improvement, comprised of all relevant entities and activities, including guiding principles for understanding, defining, capturing, documenting and categorising how various parts and processes of a complex system work together to achieve desired objectives (Fullan 2007:36; Ternes 2012:25). This study sets out to develop a planning tool and not a system-wide comprehensive plan.

The results of the literature review provide evidence of the value of $\mathrm{CI}$ in decision-making. CI has long been recognised as a strategic management tool and is one of the fastest growing fields in the business world (Schiefer 2013:9; Ghannay \& Mamlouk 2015:35). Globalisation and the development of the future competitive environment is one of the key factors affecting the growth of the CI practice (Bartes 2014a:1234). Although the literature provides evidence for a relationship between CI and strategic management, it is not clear whether the synergy between strategic management and $\mathrm{CI}$ is recognised by decision makers to their benefit. Also, it is not clear how much value is placed on CI by business leaders in terms of CI's contribution to strategy development and decision-making processes, the organisation's quest for competitive advantage and on its overall success. For CI professionals to have the greatest contribution to their clients, i.e. decision makers, they need an understanding of the nature of those needs and insight into how their CI outputs are used by decision makers. Armed with this knowledge, CI professionals will be able to design CI services that truly meet decision makers' CI needs.

Key findings of the empirical research are that managers and executives at the case organisation, in this paper referred to as the FI, place considerable value on CI in terms of its contribution to strategy development, decision-making, gaining advantage over competitors and enhancing the financial performance of the organisation. The following 12 themes emerged from the data.

\section{Understanding of the role of competitive intelligence in strategic management [\#1]}

Managers and executives at the FI were in unquestionable agreement on the statements implying synergy between strategic management and CI, but CI professionals should not assume that decision makers with evident understanding of strategic management, will also understand the role of CI in strategic management. More specifically, CI professionals should begin by ensuring that decision makers know what is meant by $\mathrm{CI}$, that is, $\mathrm{CI}$ as a service, process, product and capability.

\section{Value placed on competitive intelligence by decision makers [\#2]}

Managers and executives at the FI placed considerable value on $\mathrm{CI}$ in terms of its contribution to strategy development, 
decision-making, gaining advantage over competitors, and enhancing the financial performance of the FI and therefore to the overall success of the FI. However, relatively lower percentages were recorded for both managers and executives in terms of indicating that $\mathrm{CI}$ is very important to enhancing the FI's financial performance (cf. Gulwa 2015:39-92).

\section{Use of competitive intelligence in decision-making [\#3]}

Managers and executives at the FI most often used CI for strategic and operational decision-making - this was established through data collected and analysed using quantitative data analysis techniques in qualitative inquiry (cf. Gulwa 2015:39-92), which is essential for the inductive integrity of the findings. This study finds that the growing competition on world markets increases the demands on the information needs of managers and executives which exact the subsequent increase in the level of use of CI.

\section{Identifying the actual competitive intelligence needs of decision makers [\#4]}

Identifying the actual CI needs of decision makers entails knowing their preferred frequency intervals of obtaining intelligence on diverse topics, as illustrated in Figure 1. For example, the most important topics relating to the FI's competitive environment were political developments, macroeconomic trends, changing customer needs, legal/ regulatory changes, local competitors and operational risk, but not at the same frequency intervals, also varying at executive and manager decision-making levels.

Figure 1 informs the development of a planning tool for $\mathrm{CI}$ professionals. In their planning, CI professionals have to make provision for determining decision makers' frequency preferences with reference to receiving intelligence on specific topics at different decision-making levels at varying intervals.

\section{Extent to which competitive intelligence needs of decision makers are being met [\#5]}

A planning tool for CI should include a measure of determining the gap between what intelligence decision makers require, and what they are actually receiving. For example, gap analysis could be done to determine if there is discrepancy between what managers and executives require in terms of the elements of the financial services industry competitive environment and the topics specific to competitors. The gap analysis, presented in Figure 2, focused on what CI is required and received monthly as this is the interval that was preferred overall by both respondent groups.

For example, in terms of the priority elements of the financial services competitive environment, it was found that on changing customer needs, the gap is significant for both managers (27.8) and executives (27) in terms of what they require and currently received monthly (Figure 2). The case organisation has a number of teams that are mandated to develop this type of intelligence. However, based on the gap analysis it would seem that their outputs are not successfully reaching the FI's managers and executives.

In relation to intelligence on legal and/or regulatory changes, the needs of executives are being met as there is only a gap of 3.2. However, those of managers are not being met as a gap of 26.2 was recorded (Figure 2). Insights on legal and/or regulatory changes are largely developed by legal teams that are attached to specific business units within the company. Based on the results of the gap analysis, it would seem that their outputs are not reaching managers and executives in areas of the organisation outside the teams the legal staff are attached to.

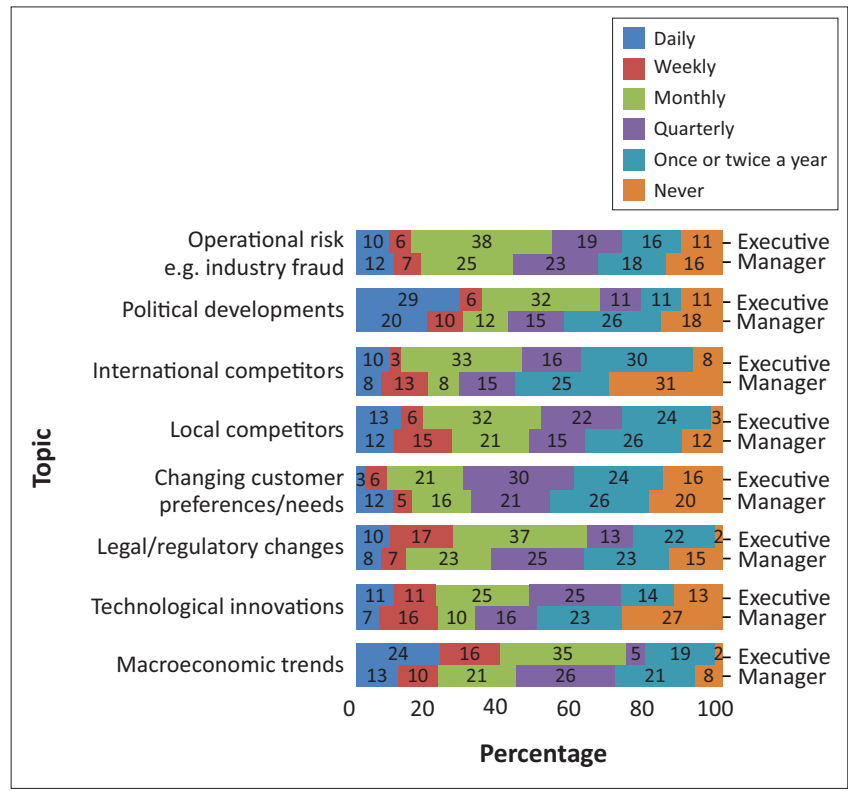

FIGURE 1: Comparison of frequency preference to receiving intelligence on specific topics.

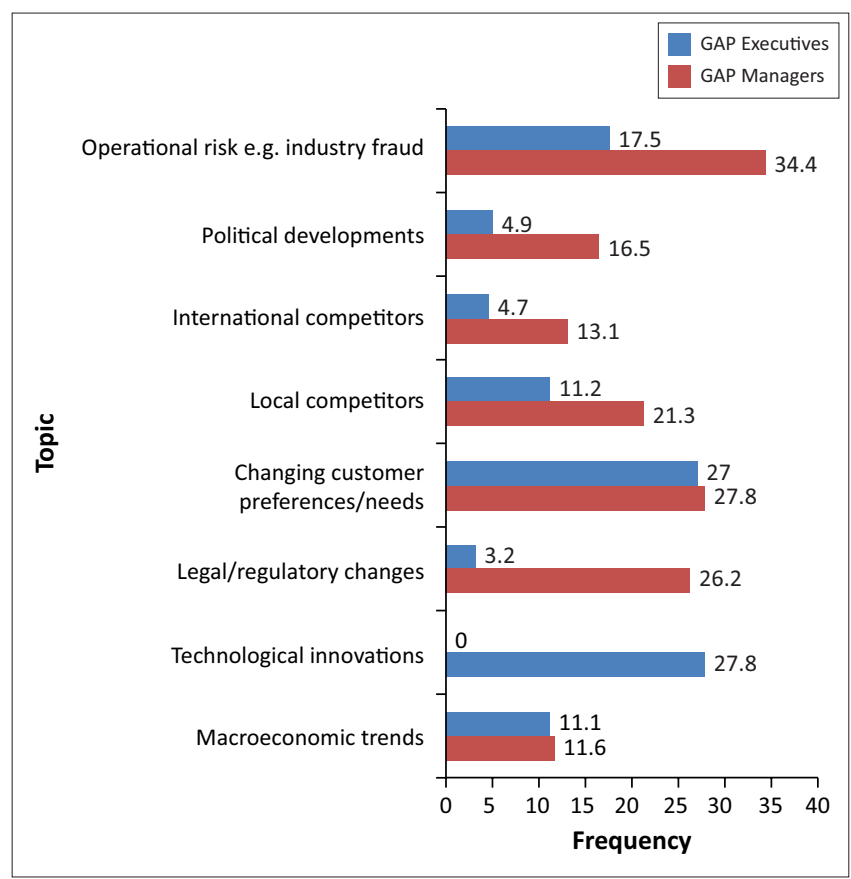

FIGURE 2: Gap between what intelligence decision makers required and what they were actually receiving. 
In addressing CI needs on local competitors, there is a gap of 21.3 in terms of intelligence received by managers and what they require. The margin is smaller in terms of executives at 11.2 on the topic of local competitors (Figure 2). Insights on this topic are developed throughout the FI, however in an uncoordinated manner. In terms of intelligence on macroeconomic trends, the CI needs of both groups of respondents are being met. The reason could be that information and intelligence on macroeconomic trends is largely available from both internal and external sources to the FI.

In terms of the priority topics that relate to competitors, the main concern was on the gap in the intelligence required and currently received on the topics on product and price comparison against competitors. Although this type of intelligence is developed in some areas of the FI, it is not done to the required extent; and, when it is done the outputs are not effectively reaching managers and executives.

The above gap analysis was discussed in order to explain the process of measuring the gap between what intelligence decision makers require, and what intelligence they are actually receiving. The process of developing a planning tool for CI professionals includes the process of gap analysis. Gap analysis is an important practice to be included in a CI strategy framework.

So far, five themes emerging from the empirical data have been analysed and discussed as themes for inclusion in the CI strategy framework. Now, the qualitative data analysis continues, further linking the empirical data and the literature review findings which incorporate the Key Intelligence Topics (KITs) process (Herring 1999:4), as well as an adaptation of the hallmarks of excellence in competitive intelligence (Best Practices 2008). The seminal work of Herring (1999) promoted the KITs process which is aimed at identification and prioritisation of CI needs of decision makers. According to Herring (1999:4-6), a company's CI needs can be generally assigned into one of three functional categories, (1) strategic decisions and actions, including the development of strategic plans and strategies, (2) earlywarning topics, including competitor initiatives, technological surprise and government actions and (3) descriptions of the key players in the specific marketplace, including competitors, customers, suppliers, regulators and potential partners, packaged in the preferred format in order to save the decision maker's time.

For example, executives usually would not have time to read and review large amounts of competitive data and information produced by CI teams. Rather, what they need is insight, that is, a new understanding, complete with its implications relevant to a specific business issue or topic (Fahey 2009:13). Proficiency in providing decision makers with insight begins with building strong relationships with a few customers and building a reputation based on the hallmarks of excellence as illustrated in Figure 3.

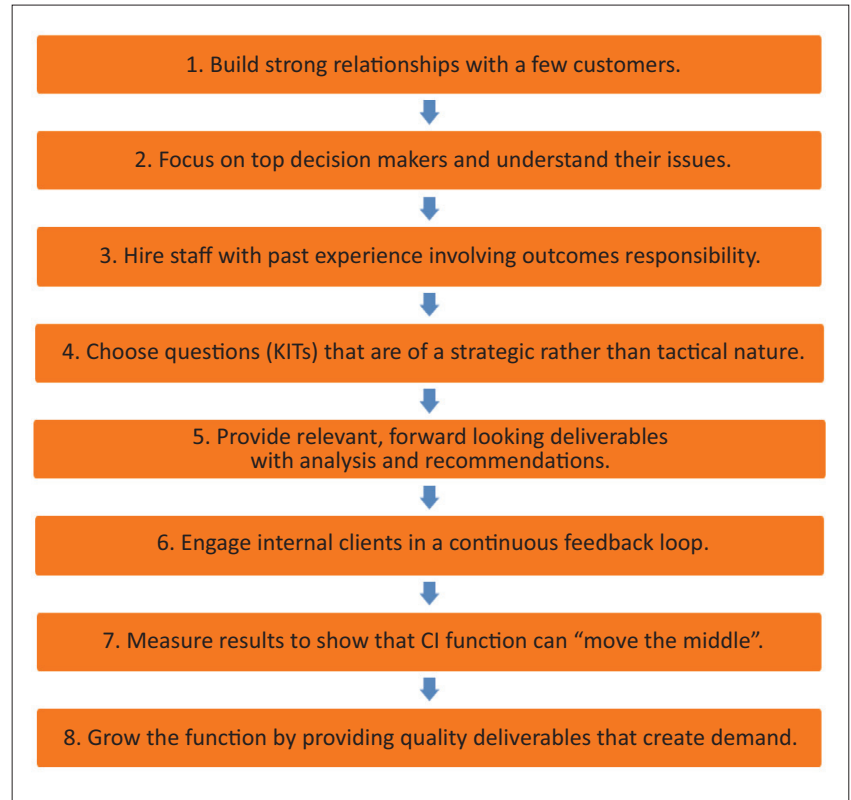

Source: Adapted from Best Practices, 2008, 'How successful companies create and develop a high-value Cl function to drive better business decisions', viewed 19 November 2015, from http://www.slideshare.net/bestpracticesllc/psm-302-a-competitive-intelligence

FIGURE 3: Hallmarks of excellence in competitive intelligence.

The comprehensive literature review conducted by Pellisier and Nenzhelele (2013:1-6), critically reviews the CI process and reiterates the hallmarks of $\mathrm{CI}$ excellence, illustrated in Figure 3. In order to achieve these hallmarks of excellence requires $\mathrm{CI}$ education. Also, the promotion of $\mathrm{CI}$ services should be included in the CI strategy framework.

\section{Competitive intelligence education and promotion of available competitive intelligence services [\#6]}

A number of respondents indicated that they are self-reliant in terms of where they get CI from. The problem with this is the issue of duplication, where managers and executives will work on developing CI outputs that are already available somewhere else in the organisation. One reason for selfreliance could be that some managers and executives are not aware of existing CI services inside the FI. Indeed promotion of existing CI services will go a long way in resolving this problem.

The central CI team runs an internal course on CI which is aimed at upskilling employees with basic CI skills so that they can conduct their own CI when the need arises. The importance of ensuring that the CI they need is not already available somewhere else in the organisation is emphasised. However, the internal CI training programme should be run more vigorously going forward and as part of its content it should drive awareness on the role of $\mathrm{CI}$ in strategic management and successful execution of business.

\section{Auditing of available competitive intelligence services within the financial institution [\#7]}

The findings indicated that CI outputs are being created throughout the case organisation. A need exists to identify who is developing these outputs, what topics are addressed by these CI outputs, where are these outputs stored and who is currently receiving and or using these outputs. In addition, 
an audit can determine what CI reports have been acquired from external suppliers and where these reports are being stored. This will help ensure that such reports, usually purchased at high cost, are leveraged across the entire organisation. Furthermore, it is necessary to eliminate, or at least reduce, duplication of instances where intelligence is bought from third parties when the same intelligence has already been developed internally.

\section{Collaboration between competitive intelligence teams [\#8]}

Within the FI, a number of teams are producing CI that is focusing on specific elements of the competitive environment. For example, legal teams produce intelligence on changing regulations, market research teams produce insights on changing customer needs and the central CI team has a focus on producing intelligence pertaining to competitors. These teams need to collaborate more effectively as it is evident that their outputs are not reaching some of the managers and executives who need their outputs to support their strategic management duties.

\section{Review of scope of the central competitive intelligence team [\#9]}

Based on the topics identified by managers and executives as very important to receive intelligence on, the central CI team needs to review the topics they have been covering in their CI reports. Through quantitative data analysis it became evident that the FI's managers and executives perceive product and price comparison as the most important topics to get intelligence on, however, through gap analysis, significant gaps were found in terms of what is required and what is currently received as far as these two topics are concerned. Thus, both the process of developing a planning tool and the eventual CI strategy framework should include continuous review of the scope of the CI team.

\section{Improvement on distribution of competitive intelligence outputs [\#10]}

From the empirical data a clear observation was made of the actual CI needs of decision makers (Figure 1). As mentioned above, the use of CI was established through data collected and analysed using quantitative data analysis techniques in qualitative inquiry (Gulwa 2015:39-92), which is essential for the inductive integrity of research findings. Based on these findings, an improvement on the distribution of CI outputs is required, as recommended in the conclusion section of this paper.

\section{Capacity of the competitive intelligence team [\#11]}

A significant number of managers and executives indicated that the CI they were receiving internally was not timeous (cf. Gulwa 2015:87-88). For example, in terms of frequency requirements, decision makers mostly preferred monthly outputs (Figure 1). However, the central CI team recently had to change the frequency of its Strategic Competitive Intelligence Report to publication once every second month due to capacity challenges. Indeed, with more staff members the CI team would be in a position to again release the FI's Strategic
Competitive Intelligence Report on a monthly basis and ensure that it covers the priority topics of decision makers as per the results of this research.

\section{Presentation of research results [\#12]}

The need was identified to present these research results to the FI's managers and executives. Typically the CI cycle includes a continuous feedback loop, mentioned in this paper as the sixth hallmark of excellence (Figure 3). Again, the comprehensive literature review conducted by Pellisier and Nenzhelele (2013:1-6), emphasised both aspects of obtaining feedback as well as giving feedback, as critical CI processes. Thus, 'Presentation of research results' was identified as the last of the 12 themes emerging from the empirical study.

The above discussion has covered the research objective of investigating the CI needs of a FI's decision makers in order to develop a CI strategy framework.

\section{Competitive intelligence strategy framework}

A CI strategy framework was developed based on the data that was collected, analysed and logically arranged according to themes. Each theme forms a component of the 12-point CI strategy framework developed as a result of this study (Figure 4).

Put together, the 12 points of the CI strategy framework form a balanced approach to $\mathrm{CI}$ service delivery. CI professionals could benefit from using Figure 4 as a planning tool. Also, CI professionals could use this study as map of the process of developing a CI strategy framework. The researchers found that the centre point of the process was [\#1] understanding of

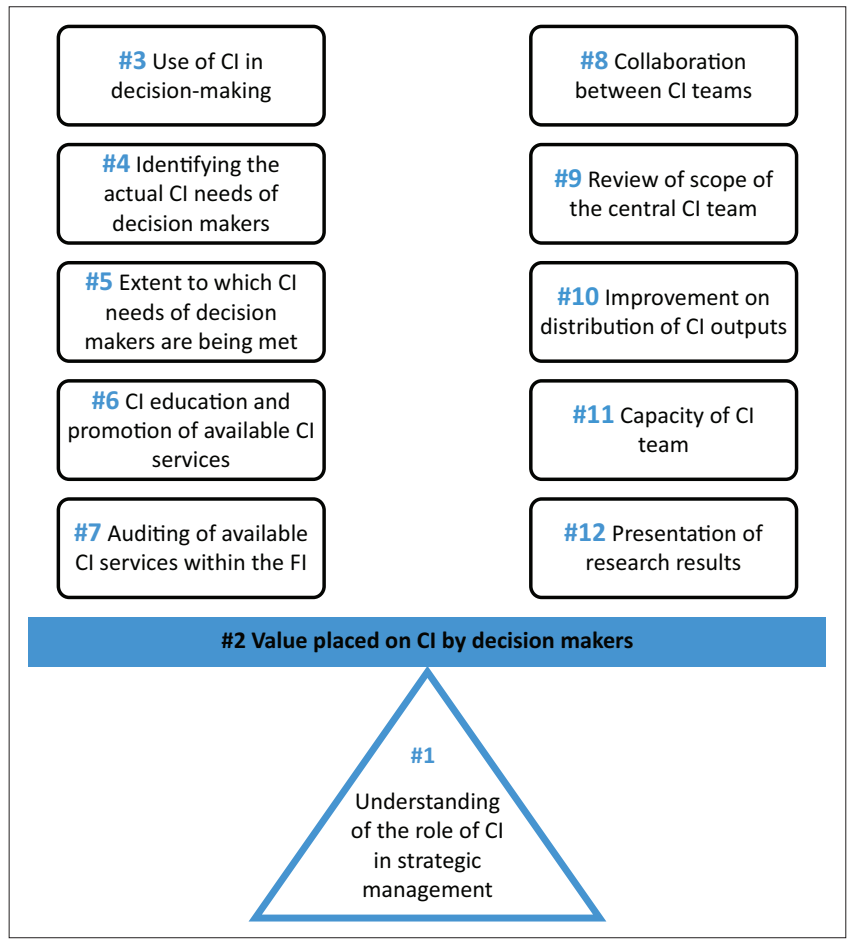

FIGURE 4: Cl strategy framework. 
the role of $\mathrm{CI}$ in strategic management on which balances, [\#2] the value decision makers place on CI; and, the value [\#2] rests squarely on the fine balancing of the other 10 points of the CI strategy framework, [\#3] to [\#12]. The emphasis is on balance; when an imbalance is noticed the relevant corrective action could be taken, for example, the case organisation may have to adjust according to the recommendations made in the concluding section of this paper.

\section{Conclusion and recommendations}

In conclusion, a FI's CI capability can be enhanced to better meet the CI needs of the organisation's decision makers when CI professionals carefully plan their approach of informing corporate decision-making. This paper presented a 12-point CI strategy framework as a planning tool for CI professionals, summarised in Figure 4. The layout of Figure 4 simultaneously serves the purpose of mapping the process of developing a CI strategy framework - emphasising that an imbalance is an indication of specific action to be taken.

This study recommends specific action in terms of [\#6] CI education and promotion of available CI services. The CI team of the case organisation should play a proactive role in educating and promoting to managers and executives the value of CI to decision-making and its contribution to the performance of the organisation. Elevated awareness through education can increase the appreciation of $\mathrm{CI}$ efforts from the CI function as well as the use of its outputs aimed at elevating synergies between $\mathrm{CI}$ and strategic management.

In terms of [\#7] auditing of available CI services, it is recommended the FI determines what CI reports have been acquired from external suppliers and where these reports are being stored. This will help ensure that such reports are leveraged across the organisation and help reduce duplication in cases where intelligence is bought from third parties.

Also, the scope of the central CI team [\#9] may need revision. Although the central CI team should continue covering the topics identified in [\#4] and [\#5], it should also ensure that it develops to a greater extent intelligence on product and price comparison against competitors. Product and price comparison were the most important topics to get intelligence on for both managers and executives and there were significant gaps in terms of what is required and what is currently received as far as these two topics are concerned. Another suggestion to ensure coverage of both priority topics on competitors as well as the elements of the financial services industry competitive environment will be for the central CI team to selectively summarise and integrate relevant insights on changing customer needs, regulatory changes and macroeconomic trends into its competitor intelligence focused reports. Doing so will ensure that the needs of decision makers are addressed in a more effective way. The new-look intelligence products as suggested in this section should then be distributed widely to cover CI needs of decision makers across business units and geographies the FI operates in.
In terms of [\#10] the improvement on distribution of CI outputs, the first step would be to compare the existing subscription lists which are used by the central CI team and other CI teams at the FI to distribute their respective outputs against the targeted sample of this research. This action will ensure that the current CI needs of these decision makers are proactively met. As an end result, decision makers will spend less time in producing their own input and rather focus their time on their core strategic management duties, thereby leveraging the synergy of CI and strategic management. In addition, a central electronic repository should be used by the central CI team and other producers of CI within the organisation. This will ensure that managers and executives across the FI are made familiar with only one source of available $\mathrm{CI}$ thus eliminating duplication of CI efforts and acquisition of CI from outside, which might already exist internally.

In terms of [\#11] increasing the capacity of the central CI team, an imbalance was noted in the ability to cover the priority topics relating to competitors in a proactive manner. A need exists for a bigger central CI team that will have more capacity to develop required intelligence products on time and distribute these across the organisation in a format that is preferred by decision makers. One preferred format was oral presentations. It is difficult to deliver on this requirement when the team has limited capacity. With more capacity the team would be able to increase its efforts in promoting collaboration of CI activities across the organisation. Lastly, it is recommended the research results are presented to decision makers [\#12] in order to achieve the fine balance of the value placed on CI by decision makers [\#2].

A number of potential areas for further research were identified. Firstly, to explore the decision-making process of managers and executives to better understand at what stage they actually use CI when making strategic and operational decisions. This will help CI teams to ensure they provide timely CI that supports decision-making. Secondly, to find out whether the managers and executives who claimed to have acquired CI reports from external suppliers had commissioned specific CI research and what CI topics did they commission on. Answers to this question will provide insights into those topics decision makers can do without. Thirdly, finding out which external newsletters managers and executives are subscribing to will help the CI team to ensure that the most useful external newsletters are shared with relevant audiences internally. In addition, this will provide insights into topics that are important for decision makers to receive information and CI on. Lastly, now that a CI strategy framework has been developed, this planning tool needs to be implemented and evaluated by the case organisation's CI professionals. Thereafter the planning tool has to be expanded into a comprehensive framework aimed at enhancing the organisation's strategic planning capabilities.

\section{Limitations of the study}

The data analysis and discussion of results present an interpretation of a single case organisation, therefore the 
findings cannot be generalised for other companies and industries. However, other organisations may benefit from the idea of a balanced process mapped out by this study.

\section{Acknowledgements Competing interests}

The authors declare that they have no financial or personal relationships which may have inappropriately influenced them in writing this article.

\section{Authors' contributions}

Briefly summarise the nature of the contribution made by each of the authors listed, along the lines of the following: T.d.P. Master's study supervisor; M.G. Master of Commerce study, with specialisation in strategic management.

\section{References}

Bartes, F., 2014a, 'Defining a basis for the new concept of competitive intelligence', Universitatis Agriculturae et Silviculturae Mendelianae Brunensis 62(6), 1233-1242. http://dx.doi.org/10.11118/actaun201462061233

Bartes, F., 2014b, 'The objectives of competitive intelligence as part of a corporate development strategy', Universitatis Agriculturae et Silviculturae Mendeliana Brunensis 62(6), 1243-1250. http://dx.doi.org/10.11118/actaun201462061243

Bauer, M.W., Gaskell, G. \& Allum, N.C., 2000, 'Quality, quantity and knowledge interests: Avoiding confusions', in W.M. Bauer \& G. Gaskell (eds.), Qualitative researching with text, image and sound: A practical handbook, pp. 3-18, Sage, London.

Begg, M. \& Du Toit, A.S.A., 2007, 'Level of importance attached to competitive intelligence at a mass import retail organisation', South African Journal of Information Management, 9(4), viewed 14 April 2014, from http://www.sajim. Information Management, 9(4), viewed 14 Apri
co.za/index.php/SAJIM/article/viewFile/196/196

Best Practices, 2008, 'How successful companies create and develop a high-value $\mathrm{Cl}$ function to drive better business decisions', viewed 19 November 2015, from http://www.slideshare.net/bestpracticesllc/psm-302-a-competitive-intelligence

Botha, D.F. \& Boon, J.A., 2008, 'Competitive intelligence in support of strategic training and learning', South African Journal of Information Management 10(3), 1-6. http://dx.doi.org/10.4102/sajim.v10i3.325

Botterhuis, L., Van der Duin, P., De Ruijter, P. \& Van Wijck, P., 2009, 'Monitoring the future: Building an early warning system for the Dutch Ministry of Justice', Futures 1-12.

Calof, J.L. \& Wright, S., 2008, 'Competitive intelligence: A practitioner, academic and interdisciplinary perspective', European Journal of Marketing 42(7/8), 717-730. $\mathrm{http}: / / \mathrm{dx}$.doi.org/10.1108/03090560810877114

Du Toit, A. \& Muller, M.L., 2004, 'Organizational structure of competitive intelligence activities: A South African case study', South African Journal of Information Management 6(3), 1-13. http://dx.doi.org/10.4102/sajim.v6i3.308

Du Toit, A.S.A. \& Sewdass, N., 2014, 'Competitive intelligence practices in Brazil: An exploratory study', Mousaion 32(1), 85-98.

Duvenage, M.A., 2010, 'Intelligence analysis in the knowledge age: An analysis of the challenges facing the practice of intelligence analysis', Master's Thesis, University of Stellenbosch.

Fahey, L., 2009, "Exploring "analytics" to make better decisions - The questions executives need to ask', Strategy \& Leadership 37(5), 12-18. http://dx.doi.org/ 10.1108/10878570910986434

Fahey, L. \& Herring, J., 2007, 'Intelligence teams', Strategy \& Leadership 35(1), 13-20. http://dx.doi.org/10.1108/10878570710717245
Fleisher, C.S. \& Wright, S., 2009, 'Examining differences in competitive intelligence practice: China, Japan, and the West', Thunderbird International Business Review 51(3), 249-261. http://dx.doi.org/10.1002/tie.20263

Fullan, M., 2007, 'Change theory as a force for school improvement (Chapter 3)', in J.M. Burger, C.F. Webber \& P. Klinck, (eds.), Intelligent leadership: Constructs for thinking education leaders, Springer, Dordrecht.

Ghannay, J.C. \& Mamlouk, Z.B.A., 2015, 'Influence of organisational culture on competitive intelligence practice: A conceptual framework', International Journa of Innovation, Management and Technology 6, 35-45.

Gould, A.M. \& Desjardins, G., 2015, 'A spring-clean of Michael Porter's Attic', Competitiveness Review 25(3), 310-323. http://dx.doi.org/10.1108/CR-04-20140008

Gulwa, M., 2015, 'Developing a competitive intelligence strategy framework', M Com minor dissertation, University of Johannesburg, Department of Business Management.

Heppes, D. \& Du Toit, A., 2009, 'Level of maturity of the competitive intelligence function: Case study of a retail bank in South Africa', Aslib Proceedings: New Information Perspectives 61(1), 48-66. http://dx.doi.org/10.1108/ 00012530910932285

Herring, J.P., 1999, 'Key intelligence process: A process to identify and define intelligence needs', Competitive Intelligence Review 10(2), 4-14. http://dx.doi. org/10.1002/(SICI)1520-6386(199932)10:2\%3C4::AID-CIR3\%3E3.0.CO;2-C

Laney, D., 2016, 'Use predictive analytics to help you capitalize on business moments', viewed 19 April 2016, from www.gartner.com

Lowenthal, M.M., 2008, 'Towards a reasonable standard for analysis: How right, how often on which issues?', Intelligence and national security 23(3), 303-315. http://dx.doi.org/10.1080/02684520802121190

Maxwell, J.A., 2010, 'Using numbers in qualitative research', Qualitative Inquiry 16(6), 475-482. http://dx.doi.org/10.1177/1077800410364740

Muller, M.L., 2006, 'Parts of competitive intelligence: Competitor intelligence', South African Journal of Information Management 8(1), 1-5. http://dx.doi.org/10.4102/ sajim.v8i1.209

Naidoo, A., 2003, 'The impact of competitive intelligence practices on strategic decision-making', Master's Dissertation, University of KwaZulu-Natal, KwaZuluNatal.

Pellisier, R. \& Nenzhelele, T.E., 2013, 'Towards a universal competitive intelligence process model', South African Journal of Information Management 15(2), 1-7. http://dx.doi.org/10.4102/sajim.v15i2.567

Sandelowski, M., Voils, C.I. \& Knafl, G., 2009, 'On quantitizing', Journal of Mixed Methods Research 3, 208-222. http://dx.doi.org/10.1177/1558689809334210

Saunders, M., Lewis, P. \& Thornhill, A., 2009, Research methods for business students, 5th ed., Prentice Hall, London.

Saunders, M., Lewis, P. \& Thornhill, A., 2012, Research methods for business students, 6 th ed., Pearson, Harlow, England.

Schiefer, C., 2013, 'Role of $\mathrm{Cl}$ in strategic purchasing decisions and its influence on suppliers resource allocation', Master's thesis, University of Twente, Berlin.

Strauss, A.C. \& Du Toit, A.S.A., 2010, 'Competitive intelligence skills needed to enhance South Africa's competitiveness', Aslib Proceedings: New Information Perspective 62(3), 302-320. http://dx.doi.org/10.1108/00012531011046925

Ternes, C.D. Jr., 2012, 'Confirming the Stankosky knowledge management framework', Doctor of Science dissertation, Faculty of Engineering and Applied Science, George Washington University.

Thomas, D.R., 2003, 'A general inductive approach for qualitative data analysis', viewed 25 April 2015, from http://www.frankumstein.com/PDF/.../Inductive $\% 20$ Content $\% 20$ Analysis.pdf

Wright, S., Eid, E.R. \& Fleisher, C.S., 2009, 'Competitive intelligence in practice: Empirical evidence from the UK retail banking sector', Journal of Marketing Management 25(9/10), 941-964.

Yin, R.K., 2003, Case study research: Design and methods, 3rd ed., Sage, Thousand Oaks, CA.

Zenaide, V. \& Castro, L.T., 2015, 'Scenario of business practices in competitive intelligence within the telecommunication industry', African Journal of Business Management 9(6), 311-322. http://dx.doi.org/10.5897/AJBM2014.7653 